\title{
Kesan Harga dan Kualiti Makanan Terhadap Tahap Kepuasan Pengguna Trak Makanan (Food Truck)
}

\author{
Azzamurni Mohtar ${ }^{l}$ and Suhaini Hj Mat Daud ${ }^{2}$ \\ ${ }^{1}$ Commerce Depatment, Politeknik Sultan Abdul Halim Muadzam Shah, Jitra, Kedah, \\ Malaysia, \\ ${ }^{2}$ Commerce Department, POLIMAS,
}

\begin{abstract}
Perniagaan dengan menggunakan trak makanan (food truck) semakin popular dan menjadi satu trend perniagaan di Malaysia. Perniagaan trak makanan merupakan satu cabang perniagaan bagi usahawan perusahaan kecil dan sederhana (PKS). Kajian ini telah dilaksanakan untuk mengenalpasti kesan factor harga dan kualiti makanan terhadap tahap kepuasan pengguna untuk trak makanan (food truck). Kedah kutipan data yang digunakan untuk kajian ini adalah dengan menggunakan boranf soal selidik daripada 100 orang pengguna trak makanan di Kedah. Data kajian yang diperolehi telah dianalisis menggunakan perisian IBM SPSS versi 22. Hasil kajian mendapati factor harga dan kualiti makanan mempengaruhi tahap kepuasan penguna terhadap Trak Makanan.
\end{abstract}

Kata Kunci: Trak Makanan (Food Truck), Harga, Kualiti Makanan, Tahap Kepuasan

\section{PENGENALAN}

Industri makanan halal adalah merupakan satu industry yang kian mendapat sambutan dan berpotensi tinggi untuk dibangunkan. Industri ini juga dilihat mampu memberikan pulangan yang lumayan kerana ia mendapat sokongan penuh Kerajaan dari aspek penyediaan prasarana pemasaran, penambahbaikan dasar, khidmat sokongan dan pengiktirafan. Ini selari dengan peningkatan permintaan terhadap makanan halal yang meningkat sebanyak USD 346.7 billion atau bersamaan dengan RM1,317 billion setahun. Pertambahan ini disebabkan oleh pertambahan populasi masyarakat Muslim di seluruh dunia, tahap pendidikan yang lebih baik serta kuasa beli yang lebih tinggi. Ia telah menyebabkan berlaku kepesatan dalam perkembangan industri makanan dan ia telah mewujudkan satu trend baru dalam industri makanan itu sendiri iaitu perniagaan makanan menggunakan trak makanan.

Di Malaysia, perniagaan trak makanan (food truck) kian mendapat sambutan dalam kalangan pengguna dan usahawan. Perniagaan dengan menggunakan trak sebagai tempat jualan adalah merupakan satu transformasi makanan jalanan yang telah menyumbang kepada gaya hidup kehidupan moden. Ini selari dengan perkembangan industri trak makanan di dunia di mana ia berkembang pada kadar $9.3 \%$ setahun (IBIS, Laporan Dunia). Perkembangan industry trak makanan bermula di Barat dan kini telah berkembang ke negaranegara Asia. Kaedah perniagaan ini tercetus hasil daripada kreativiti pemilik perniagaan makanan yang kini menjadi trend perniagaan di seluruh dunia. Biasanya, trak makanan akan dilengkapi dengan kemudahan memasak untuk menyediakan makanan. Selain daripada itu, trak makanan juga dirancang dan direka dengan kreativiti pemilik perniagaan untuk aktiviti perniagaan yang lain seperti mengambil pesanan, makan di tempat jualan (dine in) dan tempat pembayaran supaya ia kelihatan unik untuk menarik minat pelanggan. Daripada perspektif pelanggan, mereka mendapati perkhidmatan trak makanan dapat memenuhi jangkaan mereka dari aspek kepantasan perkhidmatan, nutrisi makanan sihat, kepelbagaian menu makanan dan persahabatan.

Memandangkan industri trak makanan menjadi fenomena dan telah popular di seluruh dunia, penyelidikan mengenai kepuasan adalah diperlukan. Ia adalah bertujuan untuk menilai daya saing mereka di dalam pasaran serta untuk memastikan industry trak makanan dapat menawarkan perkhidmatan terbaik untuk kepuasan pelanggan. mereka. Kepuasan

Corresponding Author: Corresponding Author: Azzamurni bt Mohtar, Suhaini Hj Mt Daud, Politeknik Sultan Abdul Halim Mu'adzam Shah. 0194256998 
pelanggan boleh didefinasikan sebagai petunjuk yang menentukan sejauhmana barangan dan perkhidmatan dan penambahbaikan syarikat yang dapat memenuhi jangkaan para pelanggan. Kepuasan pelanggan dapat diukur dengan berbagai cara dan salah satu cara mengukur kepuasan pelanggan adalah melalui harapan pelanggan tentang manfaat dan persoalan biaya bergantung pada pengalaman masa lalu yang disarankan oleh Mouri [1], dan cara lain adalah melalui kitar hayat hubungan pelanggan.

Terdapat beberapa factor yang mempengaruhi kepuasan pelanggan seperti kualiti produk dan harga. Faktor kualiti produk bukan sahaja penting kepada sector industry pembuatan tetapi juga kepada sector perkhidmatan. Produk yang berkualiti tinggi akan memberikan kesan positif kepada kepuasan pelanggan. Apabila pelanggan tidak mendapat kualiti produk yang mereka harapkan seperti sebelum mereka membuat pembelian, mereka berkecendurungan untuk beralih kepada produk atau jenama yang lain. Oleh itu, untuk membina hubungan jangka panjang dengan pengguna, syarikat perlu menawarkan produk mengikut apa yang mereka perlukan dan inginkan.

Kepuasan pengguna juga mempunyai hubungkait secara positif dengan harga. Keadilan harga secara positif akan mempengaruhi tahap kepuasan pelangga secara positif dan sebaliknya. Pelanggan melihat harga mengikut kualiti yang hasilnya memuaskan ataupun tidak. Berdasarkan pendapat beberapa penyelidik berkata pengguna biasanya akan bertukar produk kepada produk pesaing apabila terdapat kebimbangan terhadap harga.Dasar perletakan harga yang tinggi, tidak munasah dan tidak boleh dipercayai mempengaruhi tingkat kepauasan pelanggan secara negative. Pelanggan biasanya ingikan produk yang berkualiti dengan harga berpatutan yang mereka mampu dengan mudah dan jika mana-mana syarikat mampu menawarkan ini kepada mereka, makan mereka akan terus kekal dan membina hubungan jangka panjang.

\section{SOROTAN KAJIAN}

Kepuasan pengguna dan Trak Makanan Kepuasan pelanggan ditakrifkan sebagai penentu bahawa berapa barangan, khidmat, dan penambahbaikan syarikat yang dapat memenuhi jangkaan para pelanggan. Kepuasan pelanggan dapat diukur dengan berbagai cara salah satu cara mengukur kepuasan pelanggan adalah harapan pelanggan tentang manfaat dan persoalan biaya bergantung pada pengalaman masa lalu yang disarankan oleh Mouri [1], dan cara lain adalah melalui kitar hayat hubungan pelanggan.

Pada masa kini, perniagaan menggunakan trak bergerak kian mendapat perhatian daripada usahawan dan kian popular dalam kalangan pengguna. Trak makanan ini juga dikenali dengan pelbagai nama iaituTrak makanan gourmet, trak katering, penjual makanan mudah alih, dan restoran rolling atau roving. Perkataan "trak makanan" merujuk kepada pembekal makanan yang beroperasi dari kenderaan yang bergerak [2]. Penyelidik lain juga merujuk istilah "trak makanan" sebagai kenderaan bermotor tersuai yang mana pengendali menjual makanan kepada pengguna. Lori ini biasanya mengandungi kemudahan memasak yang digunakan operator untuk menyediakan makanan, dan kadang-kadang diubah suai mengikut keperluan pengguna. Trak makanan biasanya mempunyai petak untuk pemandu di hadapan kenderaan dan ruang yang lebih besar di belakang kenderaan yang digunakan operator untuk mengambil pesanan pelanggan, memasak dan menyampaikan makanan.

\section{Kualiti Makanan dan Kepuasan pelanggan}

Di dalam industry makanan, kualiti makanan adalah merupakan satu elemen yang penting yang mempengaruhi kelangsungan sesebuah perniagaan. Kualiti makanan dianggap sebagai satu faktor penting dalam kualiti restoran untuk memuaskan pelanggan dan meningkatkan kedatangan mereka ke tempat tersebut. Selain itu, juga didapati kualiti makanan menjadi faktor penting yang memberi kesan kepada pengguna.

Penyelidik seperti Asghar et al., [3] turut menyatakan bahawa kualiti makanan memainkan peranan penting dalam memenuhi keperluan pelanggan dan menentukan kejayaan industri restoran. Mereka juga menyimpulkan bahawa kualiti makanan mempunyai hubungan positif dengan kepuasan pelanggan.

Ianya turu dibuktikan melalui kajian mereka dimana terdapat kaitan positif kualiti makanan kepada kepuasan pelanggan kerana menu yang sihat dan kurang kolesterol. Kualiti makanan, kebersihan dan menu mempunyai pengaruh yang signifikan dan positif terhadap kepuasan pelanggan. Kualiti makanan terdiri daripada rasa, kesegaran makanan dan jumlah

makanan, kebersihan termasuk faktor kebersihan kawasan makan bersih dan kakitangan bersih), dan menu (paparan, pelbagai dan pengetahuan item). Berdasarkan daripada sorotan kajian, secara keseluruhannya dapat disimpulkan bahawa kualiti makanan memberikan kesan secara positif dengan kepuasan pelanggan terhadap industri trak makanan di Malaysia.

H1: Terdapat hubungan positif antara kualiti makanan dan kepuasan pelanggan terhadap industri trak makanan di Malaysia.

\section{Harga dan kepuasan pelanggan}

Pengguna biasanya cenderung menggunakan factor harga dalam membuat penilaian terhadap tahap kualiti sesuatu barangan atau perkhidmatan dan juga tahap kepuasan sama ada puas hati atau tidak puas hati. Menurut Cheng et. al., [4], terdapat dua kaedah di mana persepsi terhadap harga boleh diperolehi. Yang pertama adalah kewajaran harga iaitu situasi di mana pengguna akan merasakan harga ketika menghubungkannya dengan pesaing. Yang kedua adalah nilai untuk wang yang melibatkan kedudukan 
perbandingan pembekal perkhidmatan mengikut harga. Biasanya perkhidmatan atau produk yang berkualiti tinggi dianggap lebih mahal berbanding dengan yang berkualiti rendah [5]. Malahan ramai penyelidik bersepakat menyatakan bahawa kepuasan pelanggan diperangaruhi oleh persepsi harga. Sebab utama seseorang pelanggan itu bertukar kepada produk dan perkhidmatan pesaing adalah harga seperti harga yang tidak masuk akal, tingkat harga yang terlalu tinggi dan tidak boleh dipercayai. Oleh itu, adalah sangat penting bagi sesebuah syarikat untuk mengendalikan persepsi pelanggan mereka terhadap harga dengan menawarkan harga yang berpatutan, menarik dan rendah tanpa mengorbankan tahap kualiti produk dan perkhidmatan yang mereka tawarkan.

Berdasarkan daripada sorotan kajian yang telah dijalankan oleh penyelidik, ia menunjukkan faktor harga memberikan kesan terhadap tahap kepuasan pengguna.Oleh itu hipotesis yang kedua untuk kajian ini adalah:

$\mathrm{H} 2$ : Terdapat kesan yang positif antara factor harga dan kepuasan pelanggan terhadap industry trak makanan di Malaysia. .

\section{OBJEKTIF KAJIAN}

Terdapat dua objektif kajian ini dijalankan, iaitu:

a. Untuk menyiasat kesan faktor harga terhadap kepuasan pengguna trak makanan

b. Untuk mengenalpasti kesan faktor kualiti makanan terhadap kepuasan pengguna trak makanan.

\section{METODOLOGI KAJIAN}

Kajian ini adalah merupakan kajian cross sectional dan menggunakan data primer. Sebanyak 200 borang soal selidik telah diedarkan kepada 200 orang responden yang mengunjungi trak makanan untuk membeli makanan dan minuman di Alor Star. Data yang diperolehi dianalisis menggunakan perisian IBMSPSS versi 23.

\section{ANALISIS KAJIAN}

Data yang diperolehi telah dianalisis menggunakan perisian IBM-SPSS versi 23. Dapatan kajian menunjukkan responden kajian ini terdiri dari 66 orang lelaki dan 134 orang perempuan. Manakala pelanggan melayu adalah pelanggan yang paling ramai iaitu seramai 177 (88.5\%) orang, berbangsa Cina seramai 13 orang $(6.5 \%)$ dan bangsa India seramai 10 orang (5\%). Majoriti pelanggan adalah berumur 20-29 tahun (68.5\%), diikuti oleh pelanggan yan berumur 19 tahun dan kebawah (23\%), 40 - 49 tahun (5\%), 30 - 39 tahun $(3 \%)$ dan 50 tahun dan ke atas $(0.5 \%)$.

\begin{tabular}{|c|c|c|c|}
\hline & & Kekerapan & Peratus \\
\hline \multirow[t]{2}{*}{ Jantina } & Lelaki & 66 & 33 \\
\hline & Perempuan & 134 & 67 \\
\hline \multirow[t]{5}{*}{ Umur } & $\begin{array}{c}19 \text { tahun ke } \\
\text { bawah }\end{array}$ & 46 & 23 \\
\hline & $\begin{array}{c}20-29 \\
\text { tahun }\end{array}$ & 137 & 68.5 \\
\hline & $\begin{array}{c}30-39 \\
\text { tahun }\end{array}$ & 6 & 3 \\
\hline & $\begin{array}{c}40-49 \\
\text { tahun }\end{array}$ & 10 & 5 \\
\hline & $\begin{array}{c}50 \text { tahun dan } \\
\text { ke atas }\end{array}$ & 1 & 0.5 \\
\hline \multirow[t]{3}{*}{ Bangsa } & Melayu & 177 & 88.5 \\
\hline & Cina & 13 & 6.5 \\
\hline & India & 10 & 5 \\
\hline \multirow[t]{2}{*}{ Status } & Bujang & 180 & 90 \\
\hline & Berkahwin & 20 & 10 \\
\hline
\end{tabular}

\section{KESIMPULAN}

Berdasarkan dapatan kajian ini, terdapat beberapa saranan dan pandangan kepada usahawan, pihak-pihak berkepentingan dan kerajaan untuk penambahbaikan. Di sisi akademik, kajian ini memberi sumbangan besar kepada kepuasan pelanggan dengan meneroka kesan kualiti makanan dan harga bagi makanan di trak makanan. Bagi perspektif kerajaan, kajian ini akan dapat menampung bagaimana mengurus dan mengawal perniagaan dan aktiviti trak makanan. Dari gambaran keseluruhan pengamal, kajian ini berkongsi peranan penting yang berpengaruh terhadap kepuasan pelanggan, oleh itu pemilik atau pengurus runcit dapat mencari cara untuk menarik dan mempertahankan pelanggan

\section{RUJUKAN}

[1] Mouri, N. (2005). An Examination of Consumer Value, Satisfaction and Post-purchase behavior. University of Central Florida , 156

[2] Hernández-López, E. (2011). LA's Taco Truck War: How Law Cooks Food Culture Contests. The University of Miami Inter-American Law Review.

[3] Asghar Afshar Jahanshahi, Mohammad Ali and Khaled Nawaser (2011). Study the Effect of customer service and product quality on customer satisfaction and loyalty. Paripex Indian Journal Of Research, 3(8), pp.191-194.

[4] Cheng, T. C., Lai, L. C., \& Yeung, A. C. (2008). The Driving Forces of Customer Loyalty: A Study of Internet Service Providersin Hong Kong. International Journal of E-Business Research, 26-42

[5] Chitty, B., Ward, S., \& Chua, C. (2007). An application of the ECSI model as a predictor of satisfaction and loyalty for backpacker hostels. Marketing Intelligenceand Planning , 563-580. 